\title{
Three years in the life of UK national information policy - the politics and process of policy development
}

\author{
Steve Saxby \\ Faculty of Business and Law, \\ University of Southampton, \\ SO17 1BJ, UK \\ E-mail: S.J.Saxby@soton.ac.uk
}

\begin{abstract}
In three years since Ed Mayo's and Tom Steinberg's 'Power of Information Review', much attention has been focused on UK national information policy (NIP) as to how to render it fit for purpose in a Gov 2.0 environment. Since 2007, the importance of collecting, creating and sharing information in different formats has been a feature of policy. Despite these austere times, the intractable problem of funding public sector information provision, particularly from the trading funds, such as Ordnance Survey, has been under review. Problems continue, however, in translating the desire for reform into reality. At a time when a new coalition government is establishing policy, the fragility of these cross-government agendas can be seen. What is needed now is a clear understanding of how NIP feeds into broader ambitions of the knowledge economy, and how spatial information, data sharing and its exploitation can be used to promote better policies, facilitate social reform and build smarter government in the process.
\end{abstract}

Keywords: UK national information policy; Gov 2.0; power of information review; trading funds; public sector information funding; ordinance survey; Making Public Data Public initiative; smarter government; UK.

Reference to this paper should be made as follows: Saxby, S. (xxxx) 'Three years in the life of UK national information policy - the politics and process of policy development', Int. J. Private Law, Vol. X, No. Y, pp.000-000.

Biographical notes: Stephen Saxby is a Professor of IT Law and Public Policy and the Deputy Head of School (Research) at the School of Law within the Faculty of Business and Law, University of Southampton. He is also the Director of The Institute for Law and the Web at Southampton and the Editor-in-Chief of Computer Law and Security Review - The International Journal of Technology Law and Practice (Elsevier; www.compseconline.com) and the Encyclopedia of Information Technology Law (Thomson - Sweet \& Maxwell).

\section{National information policy in transition}

There is no doubt that the past three years has been a very active period of scrutiny within the government of the UK's national information policy (NIP). There have been a series of reviews and consultation documents starting with Ed Mayo's and Tom Steinberg's 
independent strategic review of the 'Power of Information'. ${ }^{1}$ To this has been added UK implementation $^{2}$ of the INSPIRE Directive, ${ }^{3}$ as a component of a wider UK Location Strategy, ${ }^{4}$ National Archives' proposals on managing digital continuity, ${ }^{5}$ and continuing scrutiny of policy options for Trading Fund operators ${ }^{6}$ - particularly that of ordnance survey (OS) and its role of providing critical geographic information (GI) to the UK. ${ }^{7}$ In other sectors of the national information infrastructure, there have been further proposals on data sharing, both from a data protection ${ }^{8}$ and exploitation of public sector information (PSI) perspective, ${ }^{9}$ additional relaxations proposed in Crown copyright licensing arrangements ${ }^{10}$ and specific legislative activity in relation to the digital economy ${ }^{11}$ and marine spatial planning. ${ }^{12}$ To tackle what was clearly an endemic problem of lax security towards PSI yet another strategy has been forthcoming ${ }^{13}$ and then there has been former Prime Minister Gordon Brown's own personal initiative, ${ }^{14}$ building on a new knowledge management strategy, ${ }^{15}$ to bring in the inventor of the world wide web, Tim Berners Lee and Professor Nigel Shadbolt of Southampton University to drive forward the Government's programme for re-use of PSI, which is further evident in the new model articulated in its smarter government strategy ('smarter government'). ${ }^{16}$

At issue, however, is the extent to which government responses to these initiatives amount to a coherent plan within a defined NIP and what more needs to be done to shape these elements into a successful UK strategy for smarter government. After recent expenses scandals, and at a time when the British people have been reflecting on the respective roles of the parliament and the executive and voting in a coalition government at a General Election, the question is how radical one can expect government to be in broadening participation in policy development and service delivery by significantly opening PSI for public access?

For any government, the challenge of the digital revolution poses significant logistical problems. It is easy to forget that it is only 20 years or so since the technology offered sufficient networking capability to enable public sector administrations to begin to think about harnessing it within its operations. The transition from the offline to the online world required a step change right across all levels of government administration. New working practices to harness ICT needed to be defined in relation to the accumulation, storage, retrieval and maintenance of data and better use made of information produced for a wide range of departmental and government purposes. This required new disciplines and many of the assumptions held within the civil service as to how things should be done had to change. Those assumptions were based upon a clear perception that the government was departmentally delivered and centrally controlled. The parliament would play an important consultative role of course, but the people 'out there' would be confined to contributions to consultation documents, engagement with their MP, some possible participation in the lobbying process and every five years or so, a vote at a General Election.

Digitisation has opened up opportunities for entirely new forms of engagement between the government and the people. From the mid 1990s, the government realised that it could communicate online to the public via websites established by departments. That process was advanced by developments in the network that brought broadband to the UK and a competitive market was created for its provision. That has grown from a static to a mobile internet connection, with the arrival of wireless network communication and the mobile devices to exploit it. Gradually, the government perceived that there were cost savings to be made in the delivery of services to the citizen and in citizen engagement with those services. This ultimately led to a refinement of policy 
towards a public sector web presence and the ultimate emergence of the three main public sector portals: 'Directgov', 'Businesslink' and 'NHS Choices' as a "primary information and transactional channels for citizens and businesses." However, recognition by the government that there were areas of policy that could be better delivered beyond the public sector or in a closer partnership with others was not yet properly understood.

In terms of the exploitation of digital technology within government itself, much of the early work was accomplished under the policy framework of e-government. This was very much concerned with the digital transition of government processes towards the use of online communication, digital storage of official information and modernisation of public sector procurement. The model was still based on the assumption that information flows were to be from the top down, which required a modest effort to free up access to PSI as part of the government's policy towards stimulating the knowledge economy. ${ }^{17}$ The focus was on technology and how it could improve transactions both with and within government. One example was picture archiving and communication systems (PACS) which meant that X-rays could be shared across hospitals and surgeries within minutes rather than hours or days. From 2005 onwards, the emphasis ceased to be on the 'e' of e-government but on what it could deliver. Transformational government, ${ }^{18}$ which came next, was about the "design of IT services more around the citizen, and the move to a shared services culture" 19 i.e., "simpler, faster, more cost effective services for citizens and businesses". ${ }^{20}$ Service transformation and devising policy to deliver it, as well as defining the respective roles of the public and private sectors were central to these goals. At its core was a desire to differentiate the delivery of these processes from e-government by emphasis upon the exploitation of technological advance.

Embedding the infrastructure and refining the processes of achieving these goals now seems to be encapsulated in the new buzzword 'Gov 2.0'. Here, the emphasis is upon an enterprise IT strategy that provides "appropriate security, scalability, and interoperability". ${ }^{21}$ Essentially, this is about the maturity of these policies ${ }^{22}$ within a more clearly defined and better understood set of objectives, including continued efforts to achieve cost savings and efficiency gains as e-government becomes 'smarter' and as ICT offers new technical solutions. ${ }^{23}$

Whilst one can understand the predominance of these drivers as the centre piece of government engagement in the digital revolution, it is important too for government to look beyond the infrastructure towards its applications and to the new models that present themselves for the delivery of policy. Until now, this has been discussed predominantly within the confines of the cost savings and efficiency gains that engagement with ICT can achieve, rather than in terms of how all this can work so as to produce better government and better policies overall. There is a further critical point to be made too, for it is important to note that, when digitisation occurred, it embedded itself upon the existing institutions and methodologies of government. The settled model of government being conducted within departments, each with their own mandate and internal processes, was not a methodology ideally suited for Gov 2.0. As such, the task has also been about understanding how existing policies, procedures, management structures and processes need to change to become more effective in the digital environment and more responsive to new techniques for formulating and delivering policy.

Evidence that this is beginning to happen can be seen from a number of small steps that have been taken recently. On the administrative front bringing together within a single organisation - OPSI - of the different elements of administration engaged in information policy has been essential. This has enabled government to examine 
information policy in the round and to better understand where the inconsistencies and weaknesses lie in the way it is operating, such as in the application of Crown copyright policy to widespread exploitation of PSI and Trading Fund models of financing information infrastructure. The difficulties, however, of persuading the Treasury to accept policy change against its own assumptions on funding, has been harder to negotiate.

Second, opening up access to raw public sector data is a further sign of change. This is because it shows that the government has begun to move beyond the conventional rationale of releasing PSI, i.e., to better inform the public or to stimulate economic activity in the value added products that emerge, but to invite broader public participation in delivery of policy that greater access to raw data offers.

Third, is the evidence that government is beginning to understand the different characteristics of data in terms of form and therefore the varied contributions they can make in supporting government tasks. One illustration of this is the recent announcement of a UK location strategy which aims to establish a framework for the exploitation of GI and the delivery of an important new policy tool applying GI techniques within conventional policy-making. This is intended to support decision making and improve our understanding of the impact of policy that can be better explained when mapped in relation to its geographic location. The UK's European obligations within the INSPIRE programme are a part of this emerging strategy. What now follows is an examination and discussion of how joined up these ambitions are and what more needs to be done to advance UK NIP further.

\section{Developing an information strategy for Gov 2.0}

It is submitted that the 'Power of Information Review', ${ }^{24}$ commissioned by the Cabinet Office and written by Tom Steinberg, ${ }^{25}$ formerly of the Prime Minister's Strategy Unit, and Ed Mayo, then Chief Executive of the National Consumer Council, was a highly significant contribution to the future direction of policy towards UK NIP and fulfilment of its potential. Up to that point, it is fair to say that government had not fully understood that the link between PSI and its exploitation went beyond its economic benefits into social and political consequences too. By allowing individuals, groups and organisations outside government to access, add value and 'mix and 'mash' data and then make this available for online consumption, this opened government's eyes to the fact that this was something of great value to government in helping to explain and achieve policy objectives more effectively than it could achieve by itself. POIR commented:

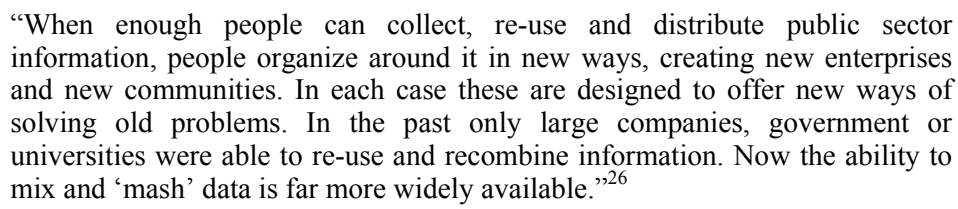

POIR went on to make what it called ' 15 practical recommendations' in line with a strategy designed to encourage government to engage with users and operators of user-generated websites 'in pursuit of social and economic objectives'; supply innovators that are re-using PSI with that information to 'maximise the long term benefits for all citizens'; and protect the public interest by helping the public to cope with the onslaught 
of information, some of which would be unreliable, and to bring excluded groups into the digital environment.

Unusually for the government, it not only responded to the report in the same month as POIR was published, but either accepted or partially accepted every one of its recommendations. ${ }^{27}$ The government agreed that the economic and social value exploitation of PSI was 'not a fad but a new social trend' and that technology had increased the scope for 'completely new uses to be made of government information', at reduced cost and with improved results in getting the information out into the relevant communities. As a further response, in 2008 , a task force was created ${ }^{28}$ to develop the original POIR agenda, monitor progress and make further recommendations. Its first and only report of February $2009^{29}$ (since it was subsequently disbanded) is again interesting in a number of respects and first because of the adoption of Web 2.0 tools in its preparation - "communicating as a web group, publishing our progress via a blog and RSS feed, and producing a draft report on a wiki". ${ }^{30}$

The taskforce develops the debate on NIP in a number of the directions described in POIR. This time, 25 recommendations were brought forward, covering a number of issues, including:

1 government to "follow their citizen customers when they ventured onto online peer support forums" and treat these now mainstream locations as "an important place in which to help citizens" 31

2 public servants to receive training and guidance in support of the new model for public and staff to "co-create information-based public services",32

3 use of new online techniques "to open up the policy dialogue online" and break away from the traditional challenge/response model of conventional consultation processes $^{33}$

4 reform geospatial data (digital maps) "for the public good and economic prosperity",34

5 modernisation of data publishing and re-use "to improve public service outcomes and create new businesses",35

6 recognition by government "that significant resourcing implications will have to be addressed if our proposed changes to the way public services work are to be successful. $^{36}$

What this shows is the belief of the taskforce of the need for government and its staff, at all levels, to transform their understanding of how public administration and delivery of policy will work in the Gov 2.0 environment. This requires a radical reassessment of the traditional assumptions that policy lies under the control of departments, that information flows must be controlled, that basic secrecy should predominate in the day to day functioning of government and that the public sector is very much about what the 'us' will do for 'them'.

Critical to the success of any transformation to the Gov 2.0 environment, is a recognition that fundamental change needs to take place in attitude, approach and policies in order to achieve this. It is not just about access to data or information and then sharing it, in which the access to data element is pushed in the hope that the rest follows. All parts of government need to understand what is involved and how it applies to them for such a 
dynamic change to work. Moreover, it is important that the government gains credit where credit is due. One civil servant commented on the point that "few would realise that the iPhone application that tells them when the next bus will arrive is thanks to government investing in digital technology ... and freeing up the data for someone to develop the application". It is important therefore not only for departments to receive this recognition as an incentive for more further such responses but for politicians also to reap such rewards.

On the issue of training, a glimpse of the Cabinet Office home page certainly suggests that the infrastructure for training is present. A national school of government exists which claims to be "a leading provider of core skills training and professional development, with a unique range of learning opportunities closely aligned with the context and priorities of government". Centres of Excellence have also been established, including a government communications network $(\mathrm{GCN})$ - i.e., "skills needed for modern professional integrated government communication"; government HR profession information guidance and news; government IT profession community space - i.e., online community "for all people working in IT in the public sector to network, collaborate and share best practice"; and a government knowledge and information management network (GKIMN) - i.e., a virtual community to share "information, ideas, expertise, news and guidance". ${ }^{37}$

Success however does not only come by creating such infrastructure. The critical test lies in an evaluation of what changes these developments have made. Such discussions as I have had with civil servants suggest that the national school of government has not achieved the impact required to keep up with the pace of change. Part of the answer here lies in making a strong and clear case for better access and use of information. A more refined case needs to be made that is, as far as possible, in tune with the individual interests of each department and to dispel the assumption, often made within large organisations, that the arguments for change do not apply to them. The task may have just become a little more urgent as one of the first acts of Prime Minister David Cameron has been to set out government plans to "open up data to the public". Commenting, the Prime Minister said:

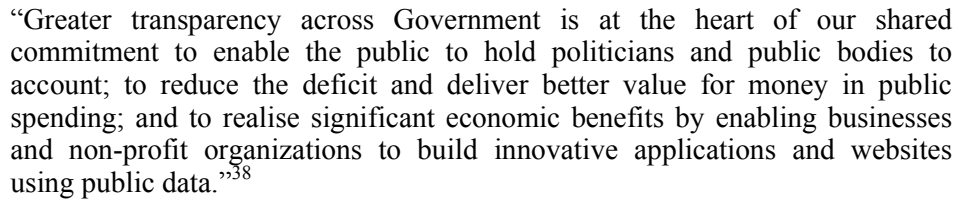
commitment to enable the public to hold politicians and public bodies to account; to reduce the deficit and deliver better value for money in public spending; and to realise significant economic benefits by enabling businesses and non-profit organizations to build innovative applications and websites using public data." 38

On the policy side, the Strategy Unit of the Cabinet Office continues to operate with the brief to provide a "cross departmental perspective on the major challenges facing the UK". It works with departments to assist in the development of their key policies and provides the Prime Minister with strategic advice and support. Since May 2006, it also maintains an office of the third sector to lead the work across government and to support the environment for a 'thriving third sector', i.e., voluntary and community groups, social enterprises, charities, cooperatives and mutuals). The aim is to enable this sector "to campaign for change, deliver public services, promote social enterprise and strengthen communities". ${ }^{39}$

With regard to IT, a central role is played by the Cabinet Office in "providing guidance and setting standards for the use of information technology in government and the delivery of government services". This includes separate strategies for ICT, digital 
channels, data sharing, access to information, which are not well coordinated, as well as an 'action plan' on open source, open standards and re-use of software; a Chief Information Officer Council "bringing together CIOs from across all parts of the public sector to address common issues"; a government IT profession to build "effective capability and capacity to deliver excellent IT" and various web guidance. There is also a Knowledge Council to provide a professional lead for knowledge and information management within the civil service.

Since the General Election of 2010, the new coalition government Minister for Cabinet Office, Francis Maude, has strengthened the role of the Government Chief Information Officer, currently held by John Suffolk, "to provide for a better integrated approach to providing the infrastructure" of ICT within government. A new CIO office is being established and one of its first tasks will be to introduce by April 2011 "a cross-departmental asset register on a common ICT infrastructure". Spending on ICT will be cut but new procurement arrangements will also be introduced to achieve better value for money. At the same time Karen Wheeler has been appointed Director of the Digital Delivery Programme within the Government Communication Group of the Cabinet Office to oversee, inter alia, the task of improving the way that the public transact with government online.

In judging the quality of training and administrative support, including input from external appointments such as the above, the central issue is the extent to which this investment is developing a better informed and committed workforce and the ability of participants, working in different parts of government, to collaborate in delivering government strategy. One of the inevitable problems of any public administration is the conflict that can arise between departments and groups over policy. If one adds a political dimension to that equation in the form of ministerial ambitions, this can lead to policy stagnation and conflict. To some degree this is inevitable. Government departments have their brief and policy development requires a robust debate. Problems can arise, however, when a departmental 'view' emerges on a policy issue that transcends ministerial responsibility or when the control of an activity requiring reform is too diversified among its stakeholders. The fundamental question, in those circumstances, is how to accept a lack of consensus and yet embed a course of action at the heart of government strategy that will not be undermined thereafter by ongoing internal disagreement.

One mechanism that does appear to have achieved a degree of success, at least in defining the issues, has been the creation of formal advisory bodies of independent advisers to appropriate ministers or departments whose judgement the government seeks. It is impossible to know how far departmental conflicts of opinion, as opposed to a straightforward need for new thinking, has motivated such appointments, as a case can always be made to bring independent advice into cross-departmental forums to coordinate established policy or advise on new ones. It must further be accepted that the appointed advisors will not always see 'eye to eye' with government when those individuals disagree with the action taken on that advice viz., recent resignations from the Advisory Council on the Misuse of Drugs, the independent expert body that advises government on drug related issues in the UK, where the controversy related to the gap between advice given and a series of government decisions and legislative changes to drugs classifications within the criminal law.

Other advisory groups have, however, fared better. Underpinning the development, for example, of information policy is the Advisory Panel on Public Sector Information (APPSI). ${ }^{40}$ This was established in April 2003 as a non-departmental public body of the 
Cabinet Office and, since October 2006, of the Ministry of Justice (then the Department of Constitutional Affairs). Despite departmental reorganisation APPSI does appear to have survived these changes and made some valuable interventions to the policy debate. Comprising experts drawn from a wide range of backgrounds from government, trading funds, the information industry and academia its remit is to:

1 “(i) advise Ministers on how to encourage and create opportunities in the information industry for greater re-use of public sector information

2 advise the Director of the Office of Public Sector Information and Controller of Her Majesty's Stationery Office about changes and opportunities in the information industry, so that the licensing of Crown copyright and public sector information is aligned with current and emerging developments

3 review and consider complaints under the Re-use of Public Sector Information Regulations 2005 and advise on the impact of the complaints procedures under those regulations".

It should also be noted that other parts of the PSI community have advisers too. There is a GI Panel in respect of GI strategy and a UK Location Council (UKLC) to support implementation of UK location strategy as a tool for delivery of policy in a number of different areas of government.

A strong indicator that the combined effect of these inputs is working came in November 2008 with the publication of a government strategy for information management. ${ }^{41}$ This was the first time that government recognised officially that knowledge and information management was now a formal function of government. The strategy was developed by the Knowledge Council comprising "senior leaders in knowledge and information management from across government" and designed to:

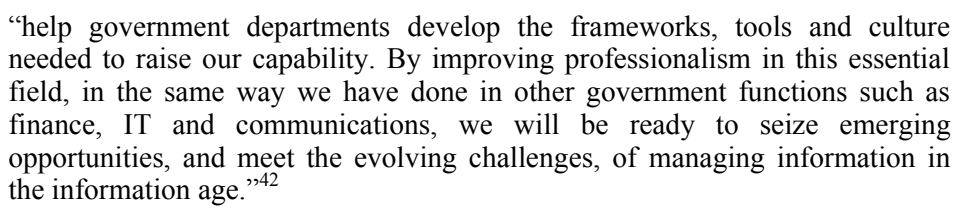
needed to raise our capability. By improving professionalism in this essential field, in the same way we have done in other government functions such as finance, IT and communications, we will be ready to seize emerging opportunities, and meet the evolving challenges, of managing information in the information age." 42

The report notes that, following the Cabinet data handling review, ${ }^{43}$ which took place after a number of breaches of information security in various parts of government, audit committees now had increased powers specifically to address information risk, both for information and information systems. Accounting officers would also address performance in information management within their annual statement and formal training programmes on handling personal data would, from now on, be required for staff. Introducing a greater degree of professionalism to the management function of knowledge and information was "critical to underpin all of this work and to raise the levels of core capability".

Looking back, it is clear now that the report sets out essential implementation plans for a new information management infrastructure that is the necessary precursor to the Berners Lee/Shadbolt 'Making Public Data Public' initiative announced in 2009. The information management strategy sums it up like this: to deliver "world-class public services and guarantee public accountability", government departments need to ensure that they capture and effectively manage information created and received. ${ }^{44}$ It would no longer be acceptable for the latter to develop individual processes "and make separate 
investments in tools and technologies to deal with the specific challenges of their own customer groups". Knowledge management should accompany good information management. It needed to be shared "appropriately and securely, using it to create better services". 45 Government policy was now becoming "more devolved and strategic challenges more complex". Civil servants and others were now increasingly working "in partnership with a number of teams, departments and organizations outside of our immediate business". In those circumstances knowledge sharing would be essential for government activity. ${ }^{46}$

\section{Smarter government}

A second indicator of change within government and of the continuing influence of POIR was the announcement by the Cabinet Office, in May 2009, of a new role of director of digital engagement (DDE). Andrew Stott was appointed as its first director to a post with responsibility now for 'transparency and digital engagement'. Up to that point, he had been the Government Deputy Chief Information Office in the Cabinet Office and had previously been responsible for the direction of the 'transformational government' programme and supporting services, including policy on government web services, on information and knowledge management strategy and on 'Power of Information' matters Since June 2010, a new Public Sector Transparency Board has existed Chaired by Frances Maude, Minister for the Cabinet Office. Its brief will be to "drive forward the government's transparency agenda, making it a core part of all government business" while "ensuring that all Whitehall departments meet the new tight deadlines set for releasing key public datasets". 47

In a presentation discussing how to extend digital engagement across government, Andrew Stott argues that we must first understand that technology is changing the way individuals receive and process information: that the growth in the use of the internet is now more accessible through policies such as 'Digital Britain'; that it is now more portable (iphone/backberry/netbooks); and with different uses (podcasts, youtube, discussions); that the decline in traditional media (print journalism struggling) is taking place; that broadcast too is changing (TV on demand/through pc); and the instant news culture is upon us. ${ }^{48}$ In addition, there are new audiences offering information to "anyone who can find it" and 'Wikipedia' and new methods of distribution - social networking, blogs (perhaps out of date now) within a 'widget economy' comprising 'ticker-style newsflashes, personalised information feeds, weather forecasts, and our 'friends' whereabouts etc. Moreover, traditional views of audience groups need to be redefined - they are now global, not just local. ${ }^{50}$

Evidence of the strength of these developments can be found in Transport for London's (TfL) recent problems the release of data about the movement of London's underground trains. Within a very short time after opening up the applications interface, the feed had to be temporarily halted after overwhelming demand for access grew 50 -fold from 180,000 to 10 million potential users. This demonstrates the interest in such opportunities, in particular developers with an interest in offering "positive, helpful suggestions for how to improve (TfL's) servicing" while "keeping Londoners on the move". ${ }^{51}$ The need for more careful planning in the build up to the release of live data needs to be recognised. 
By comparison with the 'Making Public Data Public' initiative, Andrew Stott's role is to chair the Government's Knowledge Council and work with The National Archives (TNA) in delivering both the POIR and 'Information matters' strategies. This includes increasing the civil service's use of "internal digital tools to improve cross-government co-ordination and collaboration as an aid to better policy development and service delivery". 52 By this is meant moving away from straightforward reliance upon communication to citizens on the web to communicating through new forms of digital media as the norm. The assumption is that, by embracing such media, government 'can listen and gather feedback' more easily than ever before. DDE will also continue the work to 'free up' public data (i.e., non-personal/non-sensitive data) with the broad aims of increasing transparency, "improving public services, releasing economic and social value and growth" and establishing the UK as a "global hub of skills in the future of the web". 53

If the primary emphasis of the DDE is to apply this message to the reform of the internal structures of government, Gordon Brown clearly had a further role in mind, as part of his information policy agenda, to speed up the process of reform. Perhaps accelerated by the build-up to the 2010 General Election and the need to reduce public sector costs, following the banking crisis and consequent recession, in December 2009 the government produced its manifesto for modernising government. After year long deliberations, involving much investigative work and consultation by the Berners Lee/Shadbolt expert group, the result was 'smarter government'. ${ }^{54}$ Published by the Chief Secretary to the Treasury, 'smarter government' suggests that "recasting the relationships between the centre and the frontline and between the citizen and the state and streamlining government" will improve services and help the economy grow, while reducing the current $£ 220$ billion public sector investment in goods and services. ${ }^{55}$ This follows the POIR which implicitly agrees that removing unnecessary impediments to the better use of PSI will lead to more efficient government administration, sounder policies, more efficient service provision and cost savings. That is what is found in this report. At the very heart of these proposals is the belief that its objectives can only be accomplished if radical steps are taken to "open up data and public information" and, as a result, "promote transparent and effective government and social innovation".

For this reason it is submitted that this is a milestone in information policy since the report's plans for improving public services are interwoven with commitments to open up specific datasets and make them free for re-use, including "comparative data on public service performance, citizen outcomes and value for money in achieving those outcomes". In the context of service delivery the step change that has taken place is the public sector's belief that better access to information not only means that individuals become more powerful - "an informed citizen is a powerful citizen" - and can therefore, through better understanding, raise public expectations and consequent improvements in service performance, but that workers in frontline services and the voluntary organisations that work with them will now possess "the freedom to innovate and respond to new demands in new ways".

So, in addition to setting out how government will use ICT to streamline processes, reduce costs and improve public services, it recognises that, by access to component datasets upon which policy is made, third parties too can develop new tools and resources to better inform the public and therefore act in partnership with government in achieving that objective. 'Smarter government' gives some simple examples: 
"Within a day of bike accident data being published online, it had been added to maps to help cyclists to make decisions about routes they take.... After NHS dental surgery went live, an iPhone application was created to show people the nearest surgery to any current location., 56

To facilitate this process a set of public data principles are published. Public data will be "published in reusable, machine readable form;... available and easy to find through a single easy to use online access point (www.data.gov.uk);... published using open standards and following the recommendations of the World Wide Web Consortium;... [and] will be released under open licence enabling reuse, including commercial reuse... Any 'raw' dataset will be represented in linked data form;... data underlying the Government's own websites will be published in reusable form for others to use;... and personal, classified, commercially sensitive and third-party data will continue to be protected." 57 'Smarter government' argues that such principles are necessary since the Power of Information Taskforce had concluded that even where government data was notionally available it could still be "hard to find, published in non-reusable formats or subject to licences which prevent access and reuse."

Another benefit of this approach that one glimpses in this report is the faintest recognition that the wider exposure of a broad range of raw data to enthusiastic 'data mashers', on terms that permit such integration, can lead to deeper understanding of the connections between policy components and trends and thereby support government as to how to formulate and achieve its objectives. "Smarter government" ${ }^{59}$ refers, for example, to the work of the Indian born academic and Nobel Prize winner, Amartya Sen and the precise connections he draws between the role of public services and individual advancement. $^{60}$ The assumption here is that policy will benefit from such thinking. At issue is the much broader question of how to temper politics and political ideology with the value of independent research. Faced with the completely separate challenge of the democratic process, governments rightly want to promote their own ideas, but sensible politicians and the administrations which underpin their agendas should not lose sight of the connections that can be drawn and the deeper insights gained when raw data is shared with the public at large.

A good illustration of the power of the collective mind can be found in the activities of the US-based ideas community known as technology, entertainment and design (TED). Originally focusing on TED was founded in 1984 as a private non-profit foundation. ${ }^{61}$ Since then it has developed its mission:

"We believe passionately in the power of ideas to change attitudes, lives and ultimately the world. So we're building here a clearinghouse that offers free knowledge and inspiration from the world's most inspired thinkers, and also a community of curious souls to engage with ideas and each other. This site ... [www.ted.com] ... launched in April 2007, is an ever-evolving work in progress, and you're an important part of it. Have an idea? We want to hear from you." ${ }^{62}$

Along with annual conferences in Long Beach, California and Oxford, ${ }^{63}$ the essence of TED is to spread ideas and bring together "some of world's most fascinating thinkers and doers". ${ }^{64}$ Developing its reach through a TED community, now firmly embedded in 'Web 2.0' techniques, one can see the power of this concept.

One fascinating example of what can emerge from raw data access is the insights produced by Hans Rosling, professor of global health at Sweden's Karolinska Institute. Rosling decided to track global health and poverty trends, using United Nations data and 
visualisation software $^{65}$ which he had developed. His compelling presentation ${ }^{66}$ is testimony to the benefits of exposing a variety of raw data to an informed and enquiring mind, producing insights that might have been lost if the data had not been released.

The sea change that has taken place here is that the monopoly of advice to government that was so tightly controlled within a relatively small band of MP's, consultants, lobbyists and civil servants in the off-line world, can now be exported into the hands of new communities via the much sharper and smarter environment of Gov 2.0. techniques. As a result, government now has access to a new independent resource within which both to test out and draw thinking from. At issue, however, is whether this is likely to embed itself as a permanent change of style in government in the UK and elsewhere or whether the commitment in 'smarter government' to release the majority of government-published information as 're-usable, linked data' by June 2011 will remain a political commitment post the 2010 General Election. If David Cameron's TEDTalk of February 2010 entitled 'The next age of government' is correct then the signs are that it may. He suggests that the public sector is entering a new era "where governments themselves have less power (and less money) and people empowered by technology have more" and in which the touchstones will be greater "transparency, choice and accountability". ${ }^{67}$ In addition, Gordon Brown, in a speech entitled 'Building Britain's Digital Future' given in March 2010, talked about the importance of the semantic web 'or the web of linked data' as underpinning digital transformation over the next decade. The goal was to replace "the first generation of e-government with a much more interactive second generation of digital engagement which we are calling 'Mygov'....a personalised platform allowing us to deliver universal services that are also tailored to the needs of each individual". 68

\section{The continuing problem of funding PSI provision}

At the heart of all this policy development and planning is a fundamental flaw that is only just beginning seriously to be tackled by a proper debate and action plan. Government has rightly perceived how the internet is evolving and how digital technology is opening up important new opportunities for government to reform the way it gets things done. In the UK, government has recognised that it needs an integrated policy towards the compilation, use, storage, integration and distribution of information in the ever changing environment of digital transformation. It has perceived cost savings in this process and the end of "the one-size-fits-all, man-from-the-ministry-knows-best approach to public services". ${ }^{69}$ It has further recognised the value of PSI to the digital economy and the responsibility of government, not simply to release PSI in the broad sense, but to produce the raw data itself and format it in a systematic way that will stimulate re-use in a wide variety of ways and for many different purposes.

Where the policy falls short, however, is in relation to the structures that facilitate this process. The legacy of funding arrangements, distribution policies, bureaucratic systems and practices developed in the pre-digital era, has not always reformed at a consistent pace so as to avoid 'bottlenecks' and frustrations caused by a failure to modernise. There appears to be a conflict here at the heart of policy that creates a tension between the twin tasks of creation and distribution of PSI. This arises, for example, in the varied requirements of trading funds that they should raise at least a portion of their revenues from sale of PSI to offset the operational cost to government of these services. Against 
this are the arguments that more substantial indirect gains can be achieved for the national economy from a marginal/zero cost regime for distribution of PSI, i.e., reflecting the cost of making a copy, where the benefits lie in the returns from the economic activity stimulated by such access.

APPSI comments thus on the lack of policy cohesion in this respect:

\begin{abstract}
"The Operational Efficiency Programme ${ }^{70}$ approach to addressing Trading Fund business models via the Shareholder Executive ${ }^{71}$ has been joined by the 'Making Public Data Public' initiative ${ }^{72}$ mandated by the Prime Minister. Many other relevant initiatives (e.g., the location strategy ${ }^{73}$ and Location Council ${ }^{74}$, the Information Asset Register, ${ }^{75}$ Data Grand Challenge ${ }^{76}$ ) have been launched in recent years. In addition, the Trading Funds are mandated under legislation specific to them, but also have to accommodate the Information Fair Trader Scheme $^{77}$ and Public Sector Information Re-Use Regulations ${ }^{78}$. These laws, guidance, programmes and initiatives are not closely aligned."79
\end{abstract}

It is not within the scope of this paper to review in detail once more the protracted debate about funding models for those trading funds that produce the largest revenue streams from PSI sales. ${ }^{80}$ Detailed economic analysis, has been conducted, most notably in a Cambridge University economics report (Pollock Review) commissioned by the Department of Business, Enterprise and Regulatory Reform (BERR) and HM Treasury in July 2007. ${ }^{81}$ This study found that the digital nature of PSI products among these operators implied "marginal costs of approximately zero" pricing was 'very strong'. The demand for digital data was "likely to be high and growing" and there were "likely to be large beneficial spill-overs in inducing users to innovate new services based on the data". ${ }^{83}$ In the build-up to the 2010 election the Conservative Party estimated that "the economic value of open data" based on the Pollock Report was worth " $£ 6$ billion in additional value for the UK".

What is interesting here is the impact that this study and the campaigns around $\mathrm{it}^{84}$ has had in breaking the 'log-jam' that, up to this point, had held the position on trading funds PSI sales policy. Ruth Keeling, a senior reporter within the Civil Service Live Network, offered an insider's view of the underlying political debate. In her article ${ }^{85}$, she argues that the Pollock Review was necessary because the earlier Cross-Cutting Review ${ }^{86}$ commissioned for the 2000 HM Treasury Spending Review had not considered the issue and that, according to Dr Pollock, this "was due to people horse-trading". Keeling interprets the logic of the report as arguing that "it is better for the Government to fund the maintenance of these data sets, or for trading funds to charge those responsible for making updates necessary (e.g., new firms, in the case of Companies House and road builders in the case of OS etc.), than to risk stunting innovation by charging users".

Following the Pollock review and an earlier Office of Fair Trading report ${ }^{87}$ the government announced, as part of its 2008 Budget Report, an assessment of the business strategies of the six major trading funds. ${ }^{88}$ This would be undertaken by the Shareholder Executive and HM Treasury. The conclusions were announced in the operational efficiency programme (OEP), ${ }^{89}$ as part of the Budget Report 2009. Within the remit of the 'asset management and sales' strand of the work programme, the business strategies of the relevant trading funds, starting with OS were examined. ${ }^{90}$ For the latter, it principally recommended maintaining the status quo, i.e., the self-funded licensing model would continue, but this would be alongside "reform of the organization to ensure easier access to its data and services". ${ }^{11}$ Under this model, the key challenge would be to develop a simpler licensing framework that was "fairer and more transparent for business 
and other customers". ${ }^{92}$ OPSI undertook to work with the Shareholder Executive to deliver this result.

Ruth Keeling submits that this outcome is the result of further 'horse-trading' between the parties and quotes Dr. Pollock again as saying that his report "had been watered down" and that "some trading funds were not enthusiastic (about the Pollock review) because of the loss of autonomy over charging policy that it was suggesting". ${ }^{93}$ It is clear that the whole issue has been highly contentious for OS which, in 2007, had gone as far as to hire a political lobbyist, ${ }^{94}$ ostensibly to advance its case in parliament and with the government. A leaked ministerial briefing delivered by the Chairman of OS, Sir Rob Margetts urging a 'hybrid strategy' on charging, based on figures that were subsequently criticised as failing to add-up by 'free data campaigners', led to a response from OS that this strategy had already been agreed with ministers some months before. ${ }^{95}$

For this reason, one theory suggests that the government's June 2009 announcement of the 'Making Public Data Public' initiative ${ }^{96}$ and the invitation to Professors Tim Berners Lee and Nigel Shadbolt to bring it forward, was a deliberate high level attempt to resolve a 'long standing battle' between the Cabinet Office (as supporter of more open access to PSI) and HM Treasury which preferred to see a revenue stream from trading funds as a contribution towards the cost of their activities. ${ }^{97}$ It is also suggested that Gordon Brown's announcement, on 17 November $2009,{ }^{98}$ that the government intended to explore ways of making all OS maps freely available from April 2010 "so it can be used for digital innovation and to support democratic accountability", may not have been as well received by OS Chairman, Sir Rob Margetts as the press release suggests, ${ }^{99}$ particularly as this announcement was orchestrated to coincide with the launch of a consultation process ${ }^{100}$ in which one option was to allow OS to retain its existing business strategy. $^{101}$

Discussions with representatives of the Cabinet Office suggest that the direction of debate about funding future Trading Fund PSI activity does represent dramatic change for the latter. The position thus reached in that debate is certainly regarded within the Cabinet Office as 'massive progress' and in no small part due to the pressure exerted personally by Gordon Brown to get to this position. The practical problem now is that departmental budgets have been planned ahead based on the income that trading funds planned to accrue from charging for data. This situation, combined with the coalition government's 2010 Budget announcement of further cuts of $25 \%-40 \%$ among a range of departments over the life of the parliament, has added to Trading Fund's concerns that they will not be able to deliver, in their entirety, the portfolio of PSI products and services for which they have responsibility or indeed continue to maintain their currency.

At stake here is a fundamental issue namely how to win hearts and minds as to the case for better access and use of PSI. The stakeholders, whose livelihoods and capacity to deliver PSI depend on a revenue stream built on charging for such access, are going to find it very hard to accept the principle underpinning the 'Making Public Data Public' initiative unless government can find the financial resource to sustain those stakeholders while reliance upon PSI revenues is relaxed. That will depend upon how strongly the coalition government feels about the previous government's commitments in 'smarter government' to open up specific datasets for free access and reuse and to its own agenda for greater transparency. 


\title{
5 What happens next?
}

In many respects, the PSI policy review of OS and its timing is indicative of both the strengths and weakness of UK information policy as a whole, and the political processes that must be scaled to effect change. The events since POIR show both a desire for change, but continue to demonstrate just how difficult it is to reach that goal and to put everything in place so as to make such change possible. On the democratic front, the timing of these discussions, at the point when a General Election has just led to changes in the political map of government, goes to show just how uncertain the continuity of a policy review can be. Although it may have elected to have started from a different position, the coalition government may wish to see completion of the process or alternatively, through force of circumstance or change of policy, abandon it mid flow to pursue an entirely different agenda that may effectively start the process all over again.

In the meantime, the only way forward is to reflect upon where things stand today. It is beyond the scope of this paper to engage in a detailed analysis of the consultation and findings of the OS review, but it can be summarised as intending to open to public scrutiny the strategy, ${ }^{102}$ announced at Budget 2009, "to keep the self-funded licensing model, but reform the organization to ensure easier access to its data and services". ${ }^{103}$ The rationale for the consultation was as follows:

\begin{abstract}
"Since the autumn, government has been working to develop and refine the strategic options for OS in the light of the Making Public Data Public project. ${ }^{104}$ We have heard the views of a wide range of stakeholders with an interest in this area. Some of their objectives - even within government - are conflicting. We have attempted here to set these out and identify the trade-offs and potential compromise positions." 105
\end{abstract}

The consultation offered three possible options to achieve reform. Basically, these were to carry on with the strategy as announced (Option 1); release licensing constraints entirely on large-scale data, creating a fully subsidized data collection and maintenance business (Option 2); or staged transition from the current business strategy with the eventual shift towards government paying more towards the costs of OS (Option 3). ${ }^{106}$

The outcome of that review, published in March 2010, ${ }^{107}$ concluded that no clear consensus had emerged from the responses and, in the light of that, the government would be pursuing a modified approach. First, it would proceed with its plans, announced by the Prime Minister in November $2009,{ }^{108}$ to release a range of OS data that would be free; ${ }^{109}$ secondly, to enter into a Public Sector Mapping Agreement with OS so as to establish a commercial relationship in the supply of products and services by OS to government; ${ }^{110}$ thirdly, bring in changes to OS's 'derived data' policy for the commercial sector, ${ }^{111}$ including 'free to use' data, as part of its work on revised pricing and licensing; ${ }^{112}$ and fourthly to ask OS to "take on the technical delivery role of the services that are required to meet Britain's obligations under INSPIRE"113.

In attempting to assess these developments it is understandable why the focus should be on OS as the vanguard for PSI reform. After all, it is a Trading Fund; it produces major GI products of growing importance to the digital economy and has, for some time now, been the subject of much criticism by consumers, particularly business users, as to its data access and use policies. The framework within which it operates, therefore, can be said to illustrate many of the problems and contradictions that presently typify UK PSI policy and certainly confront the objectives of the 'Making Public Data Public' initiative that had so much support from Gordon Brown, whilst Prime Minister. 
Having that said, the focus on OS, rather than upon NIP as a whole, has not been welcomed by the independent advisors on PSI policy viz., APPSI. ${ }^{114}$ In a robust analysis, ${ }^{115}$ that expresses elements of frustration with the government's focus, APPSI comments, in its response to the consultation that "a much better approach would have been to take an overview of NII and assess the real needs for GI as part of it, rather than concentrate simply on what is presently available from OS". ${ }^{116}$ For the record, and not yet aware of the government's proposed modified formula, APPSI believed that while Option 2 'provided the cleanest model' it was an 'irreversible step' and therefore 'very difficult to make work' and so favoured Option 3 'as a staging post towards it' promising a review of progress three years down the track. ${ }^{117}$ APPSI sums up its position as follows:

\begin{abstract}
"A better and more strategic approach would have been to ask what is required by way of mapping and related geographical information for government and what additional societal benefits could be derived from making available the resulting products (or spin-offs) to the public. Ideally this would be a second level question after a review of the nation's information infrastructure within which Geographical Information nests (and within which OS data nests). We cannot safely assume that what Ordnance Survey currently produces meets contemporary needs - indeed parts of the specification of some OS products dates back over 50 years - or will remain the 'data of choice'. From a strategic review of needs a rational set of specifications could have been assembled and the best way of meeting them designed and implemented."118
\end{abstract}

It is quite clear from APPSI's perspective that, if it was going to embark on this journey, it would not have started from this point. Throughout its statement one senses frustration that the bigger picture is not being grasped, which is probably due to the competing views from the parties involved, including parts of government, and the attempt to find a way through these political challenges. However, it is a reasonable point that if a small area is tackled and proof obtained that it can work then it can be rolled out later on to other areas of public information.

For its response, APPSI does try to define an agenda which, if it had its way, would like to advance. First, it wants government to appreciate that the 'rate of change of the technology' is an important factor. The scope for collection of information 'about ten (linear) times more detailed' is just a few years away while 'global commercial coverage of detailed satellite data in digital form is nearly a reality'. ${ }^{119}$ Data mining and visualisation tools are 'improving rapidly and becoming widely used' stimulating data mashing and the ability to detect the 'hidden truths' embedded in the data.

Second, it wants political recognition that, at the heart of current information policy, is a 'fundamental contradiction' exemplified in the definition of public data in 'smarter government'. ${ }^{120}$ This defines the latter as "government-held non-personal data that are collected or generated in the course of public service delivery". ${ }^{121}$ APPSI argues that such a definition implies two categories of provider:

1 "the great bulk of government organisations ....that provide that information to citizens and businesses at marginal cost or for free"

2 the relatively small number of information providers most notably the trading funds, for whom there is no "consistent philosophy behind the allocation of a body to a particular category, other than "make some money wherever we can". 
The picture is 'further muddied' says APPSI because, in some cases, "the second category organisations derive revenue from information based in part on data made available at no cost by first category organisations". It argues that engaging in specific consultation about strategic options for OS fails to deal with the situation of the other trading funds and would most likely lead to one set of rules for OS that do not apply to the others. In reaching this view APPSI states that the suggestion that all trading funds are different "and by implication need to have their own modes of operation" is 'exaggerated'. ${ }^{122}$ APPSI's preferred strategy is for the discussion about OS to be the first step towards taking the former's recommendations "from the specific to the general case for all PSI holders". ${ }^{123}$

Third, APPSI wants a clearer strategy towards GI which the Local Government Association describes, in its response to the consultation, ${ }^{124}$ as "an important, but still under exploited tool for public service planning, coordination and delivery at all levels". GI was an aid to understanding "the distinctive characteristics of place, community, economies and environments" and a vital tool for local service providers and procurers in responding to citizens' needs. APPSI argues that, what is needed now is a clearer definition of the core elements of strategy to bring GI to the fore. It points out that the "only government statements of which we are aware which define what is required is the set of core reference geographies (CRG's) listed by the Government's Location Council and the similar definitions embedded in the EU INSPIRE Directive". ${ }^{125}$ APPSI argues that these definitions are 'extremely imprecise' and must be refined if they are to serve as 'specifications of need'. This goes beyond the 'sets of information' that OS contributes, with the result that the consultation deals with "one part only of a complex and important issue - identifying what geographical information is needed to meet government's needs and provide maximum societal benefit".

\subsection{National address register}

There is one particular long standing dispute that illustrates why a broader more coherent GI strategy is needed that takes a more integrated approach towards NIP. That is the continuing absence of a maintained National Address Register in the UK. According to the Royal Statistical Society "an accurate register of addresses is a vital piece of information that underpins the nation's knowledge around a range of issues such as how public services are managed, including local taxation and emergency services". ${ }^{126}$ By way of illustration, in a report by the UK Statistics Authority in July 2009, there was criticism of the way the UK monitors migration. A key factor that hampered collection of data was the lack of an up-to-date address register ${ }^{127}$ As far back as 2003 the then Minister for Local and Regional Government was identifying the need for an 'accurate address register', but subsequent attempts by the then Office of the Deputy Prime Minister to establish a National Spatial Address Infrastructure failed because of lack of agreement among the parties involved - Royal Mail, OS and Local Government Information House (LGIH) a subsidiary of IDeA - The Improvement and Development Agency. ${ }^{128}$

The present dataset is the National Land and Property Gazetteer (NLPG). This is compiled "in partnership with local authorities, which have a statutory duty to create addresses, and maintained on (IDeA's behalf) by a private sector partner Intelligent Addressing". The result is a scheme whereby the data is shared with local authorities, police, fire services and others at no charge, but other organisations may only access the 
database on payment under licence. ${ }^{129}$ One consequence of the lack of clarity has been threats of legal action by Royal Mail to stop 'unauthorised access' to its postcode data. ${ }^{130}$ A typical licence for access to a regularly updated list of 1.7 million postcodes costs up to $£ 4,000$. $^{131}$

Question 9 of the consultation invited comments on the proposal that such a register be established and suggestions for mechanisms to deliver it. The government response reports that a large majority of those who commented 'were supportive'; identified a number of benefits in having a register and were 'critical of current arrangements' - in particular the collective costs of multiple systems, a lack of a 'definitive national dataset' and the failure to act upon the Location Strategy report, since it had identified a National Address Register as one of the 'Core Reference Geographies'. ${ }^{132}$

The key problem here is that no single authority has control of spatial information. Whereas Royal Mail owns the post code data, located in the postcode address file (PAF), OS provides the coordinates for each PAF address, while local authorities control street naming. The 'complex interactions' of different intellectual property rights that reside among these participants and the licensing barriers that have been erected represent the biggest single impediment to progress towards the register. ${ }^{133}$ APPSI's response has been to say that the situation 'must be resolved' and that it is a "national scandal that we do not have a definitive National Address Register, when most of the components have long resided in the public sector" and when an 'integrated solution' already exists in Northern Ireland. It welcomed what it understood to be the position, namely that the Department of the Environment, Food and Rural Affairs (DEFRA) now had "the leadership in re-examining a National Address Register". APPSI hoped that "the many reports on this over the last 10 years will lead to speedy action and... a programmed timetable for this as soon as possible". 134

The untenable position from a public policy perspective of the present impasse over the formation of a National Address Register can be seen in the build up to the 2011 census. The Select Committee on Treasury commented in its report in 2008 that:

\footnotetext{
"To improve the accuracy of the census a reliable address register is needed to identify people living in particular homes. We asked the Exchequer Secretary why no progress had been made to develop a national address register. The Exchequer Secretary said that there was no "easy answer to that. As you know, there are three different sources of address registers. We have never had a national address register'.,135
}

In addition to the distributed nature of the intellectual property rights among the three contributors to the data, one can also see how different stakeholders within the public sector, all with legitimate interests in establishing the register, are calling for action, but without the power to implement it. The Office of National Statistics (ONS) has responsibility for conducting the Census that has taken place in the UK every ten years from 1801 to 2001 with the exception of 1941 . The business case for the census is the " $£ 100$ billion per annum allocated from central government to local authorities and to NHS Primary Care Trusts" and the need for this money to be "distributed appropriately between different parts of the country to meet the needs of local populations". ${ }^{136}$

In order to resolve conflicts between the draft address register to be used by ONS in distributing the Census questionnaire to households, it was noted that approximately $£ 10$ million had been spent by ONS purchasing data from Royal Mail, OS and local authorities. The Treasury Select Committee, reporting on evidence from Professor David Martin in 2008, said that "the current competition between the NLPG and OS address 
products was a major threat to the census operation". Each system had "different strengths and weaknesses and there was no strategy for integration". ONS had proposed "a comprehensive national address check, in the run-up to the census; 'yet this entire expensive process would be unnecessary if a single definitive national address list were maintained, in which case much of the address checking resource could be devoted to other aspects of census data collection and production"." ${ }^{137}$

In a progress report on the build-up to the census, published at the end of March $2010,{ }^{138}$ the London Regional Committee ${ }^{139}$ reported that the address register was 'progressing well' and that 46,000 anomalies between the address register and local authority databases and more than 51,000 anomalies between the draft register and Royal Mail's address database had been rectified. ${ }^{140}$ The committee also reported that it was their understanding that the expenditure on the address register so created was not to be exploited thereafter "despite the time and effort that has gone into establishing and updating it". If this was the case then it was "barely credible that this valuable resource is not to be maintained after 2011 ".

No comfort could be found on this point either in the government's response to the OS consultation. There was a conspicuous absence of discussion as to any future plans the government might have in mind when it summarised public responses to Question 9, i.e., the proposal for such a register.

David Cameron, in his election campaign, talked a great deal about eradicating 'waste' within the public sector. The real test comes, however, when the time comes to convert the rhetoric into decisions and action. The problem here lies in the lack of overall control of the problem in hand. Each of the stakeholders wishes to protect their position with the result that a 'stand-off' occurs. Given the importance that parliament, the expert advisors and individual public sector bodies have given to a resolution of this conflict one can only hope that the coalition government remains true to its word and that a fully maintained and freely available National Address Register emerges in the near future.

\section{Other outstanding issues in NIP}

If government believes that resolving the funding issues surrounding PSI provision, reforming strategy on information sharing and bringing training in information management up to date within the public sector suffices, then this will be only part of the story with regard to what needs to be investigated within the framework of NIP. To begin with GI is rapidly becoming a critical subset of PSI upon which much untapped potential awaits to be realised. This is true both in terms of the digital economy and public service provision, but also in relation to better informed policy-making, development of the UK Location Programme, ${ }^{141}$ marine spatial planning ${ }^{142}$ and the UK's domestic implementation of the INSPIRE Directive that deals with an infrastructure for spatial information in Europe. ${ }^{143}$ In the latter case plans by the UK Location Council to establish a 'UK geoportal' on the Web by April 2011, as a single source of UK geographic data, seems to have been shelved by the new coalition government in favour of 'data gov' as the portal of choice. This raises issues about how the INSPIRE requirements will be met and whether 'data gov' is really the new model when some argue that it is not user friendly for non-developers and that its purposes are still unclear. On top of that, there are continuing questions about archiving PSI, its funding, intellectual property rights and policies, especially in the case of 'born digital' works. ${ }^{144}$ There are also new partnerships 
out there involving public, private and third sector organisations that are working in a wide range of archival, policy making and information sharing environments. ${ }^{145}$ The government needs to be sensitive to the needs of these enterprises and, where it can, to facilitate and promote collaboration. Seeing and understanding the bigger picture, therefore, is vitally important.

One illustration of how government and perhaps the Civil Service may, nevertheless, be learning from past mistakes is what appears to have happened to official websites in the immediate aftermath of the 2010 election. The BBC reported that "mouse-wielding civil servants across Whitehall are engaged in a frantic rush to archive old pages full of defunct policies and pen portraits of now departed Labour ministers and to replace them with shiny new web pages that reflect the priorities and personalities of their new political masters". 146 The BBC said that it was given to understand that "all material relating to the previous administration" had been moved to TNA. This includes all promotion of old policies, such as identity cards, where the new political message indicates an intent to cancel the programme. The author of the article, the political reporter for the BBC Brian Wheeler, commented:

"This is the first time we have had a change of government in the internet age. When Labour came to power in 1997, government departments were just beginning to feel their way on the web. Just how much has changed can be seen from the newly released archive pages charting the development of government websites during 13 years of Labour rule. Historic moments such as the May 1997 decision to hand control of interest rates to the Bank of England are captured on the Treasury website from that time. Other historic government websites, including early versions of the Downing Street site, are available to view on the National Archives website." 147

The contrast with 1997 is clear from the remarks of one attendee who was present at a government briefing of Official Publications librarians at that time:

"I went to a meeting of OP's librarians, where some hapless civil servant from MAFF (Ministry of Agriculture, Fisheries and Food) told us that the day after Blair was elected they ditched everything on their website which related to the previous administration. She clearly felt this was a good thing, so was alarmed that this statement was met with about 100 hisses of disgust and howls of anguish, and took some convincing that there was value in those old documents."

What is clear is that TNA is now aware of the problem and has, for the past seven years regularly "been trawling 1,500 websites, three times a year, to take screen shots for its archives, which can be viewed by the public on its website". ${ }^{148}$ In the meantime, one of the first acts of the new Minister has been a pledge "to scrap hundreds of unnecessary and expensive government websites and slash the cost of the remaining sites to save millions of pounds". All 820 government-funded sites will be reviewed as to cost and uses to assess whether resources could be shared more effectively. The plan will be to remove up to $75 \%$ of sites and reduce running costs of some $50 \%$ of the remainder. Working with the coalition government as 'digital champion' will be internet entrepreneur Martha Lane Fox with a brief to 'transform government websites' as part of government plans to "put key public services online and to increase the number of people who are able to use the internet". Emphasis will also be placed on "sharing resources and facilities and using low-cost open source products to reduce running costs". It is hoped that this proposal will not lead to a lessening of government commitments on transparency and the agenda of 
smarter government but the retention of 'high quality services' which it says this programme of cuts will deliver. ${ }^{149}$ TNA will also need to ensure that appropriate records of these soon to be removed sites are archived.

\section{Conclusions}

It is abundantly clear that, in the latter stages of the Brown administration, progress was being made at many different levels of government in understanding the need for an NIP that delivered more on value. It is not that difficult to pinpoint how the development of this policy began to accelerate in the past three years. If POIR ${ }^{150}$ was the 'wake up' call that government needed, technological advance in ICT was the catalyst. Government began to see how important sharing PSI could be. It was not simply about the provision of useful information from within the public services that would better serve individuals while at the same time reducing costs; it was also about the opportunity this would offer private and third sector users to add value to that data.

What is clear, however, is that Gordon Brown commitment was to embrace digital transformation no matter what. David Cameron appears to take a more pragmatic view and will support it for the results it will deliver, particularly in terms of greater transparency across government which he sees as an outcome likely to expose inefficiencies in government administration and, one would hope, among policies as well. For the first time one sees recognition on the part of government that, by exposing abstract data to the collective public mind, new knowledge can be gained through better understanding of the data, the causal relationships between it and new visualisation techniques available to present it. The 'smarter government' agenda ${ }^{151}$ seems to be saying that, in this respect, with the new ICT tools that are now available, government should no longer operate upon the assumption that policy and action was always a top down process in which the public sector created all the information. Instead there should be a shared culture in which opportunities are created for development of ideas from individuals and partnerships that extend beyond the traditional mechanisms of lobbyists, of parliament and periodic consultation processes that take place at various stages of policy development.

Broadening the scope for public input and initiative is an inevitable consequence of the 'Making Public Data Public' initiative. ${ }^{152}$ Although in its very early stages and assuming that the project continues, it does suggest a desire within government to see where this could lead. The critical issue now, post the General Election, is to see whether this was fundamentally Gordon Brown's idea or a reflection of a broader commitment within the Cabinet Office and beyond for change. A consequence of this initiative is that government must be prepared for more informed criticism of policies where those policies, according to the released data, appear to be failing or revealing where improvements can be made. To that extent it fits David Cameron's desire for transparency and challenges existing practices whereby, on the whole, government has normally chosen to do this in private, taking confidential advice from civil servants, lobbyists, consultants or from within the staged political arena of the parliament. By embarking on a process of sharing raw data there is a much greater chance that government will be found out and that, on occasions, its policies will be found wanting. 
In some respects, however, the Berners Lee/Shadbolt initiative does not go far enough in terms of presenting the case for change. As pioneers of the programme, the danger is that, as individuals, they will be labelled as 'geeks' presenting a message that a majority of civil servants, technologically outdated in thinking and experience, simply do not understand or if they do, are not persuaded to accept. This includes trading funds, perhaps, who cannot see where funding will come from if their outputs are to be given away and who do not want this sea change to erode their existing controls over PSI as a source of revenue. That challenge remains. What is required perhaps is a refinement of that message so that the case for better access and use of PSI within government and beyond is tailored to departmental circumstances. Such an approach would explain why, to take the Ministry of Defence as an example, it is in the specific interests of the ministers and civil servants in that department to get fully behind the initiative.

Taking all this into account, the reward for exposing PSI to greater public scrutiny is the prospect of better policy and improved cognition of the causal relationships involved its elements. This does not mean an abrogation of responsibility on the part of government, but a desire to engage the public mind more effectively and recognise that it is an untapped resource whose time has come. If this is really underway then both government and civil service are on a learning curve from which best practice will need to be developed. It will place greater pressure upon the infrastructure that advises government on policy, as information flows will need to be managed and data interpreted from a much wider range of sources than has traditionally been the case. The continued use of advisory groups such as APPSI, the GI Panel, UK Location Council etc., merging expertise from a wide range of backgrounds is likely to offer much in support of the new processes of policy development and analysis that may emerge.

Given that politics and force of circumstance will ultimately determine the speed and direction of change within government, it is of course quite possible that these particular initiatives will be swept away in the short term, particularly as departments become centred upon the delivery of the $25 \%-40 \%$ budgetary cuts called for by the coalition government over the lifetime of this parliament. However, the ultimate drift towards such new methodologies is unlikely to be reversed, particularly on some of the specific issues that have been under debate and scrutiny for some time. APPSI is pressing strongly for a more coherent approach towards PSI and, in particular, with regard to GI. ${ }^{153}$ What is needed now is a strategy for the development, maintenance and distribution of core information products that does not work against itself due to the spread of rights, interests and funding models governing its providers. The government needs to focus on where these problems exist and endeavour to resolve them through clear leadership, built on a strategy that embraces the logic of its purpose - better policy, an engaged public mind and a thriving digital economy. Informal discussions with representatives from Cabinet Office would agree that one of the impediments to progress is parliament itself. The suggestion is made that MP's really do not recognise how old-fashioned the Palace of Westminster has become in the digital age and how poor their collective knowledge is of the impact of ICT: 'they simply don't get it!' The arguments for change need to be more effectively communicated and made relevant, both within and outside government, which is hard for an institution like Parliament to grasp 'that barely even uses computers'.

On top of all this, there are broader issues that require more detailed legislative scrutiny and, in some cases, international consensus if NIP is to develop. Further, reform of copyright law is going to be required in the longer term to deal with some of the intractable issues that arise when the desire to develop and share information products, 
maintain datasets and create derivative works hits licensing problems associated with the copyright interests involved. The Digital Economy Act $2010^{154}$ has not addressed these questions, so eyes will now turn to EU analysis ${ }^{155}$ of copyright and its role in the knowledge economy and World Intellectual Property Organisation (WIPO) concerns to develop "the infrastructure of the international intellectual property system as a means of increasing participation in the knowledge economy and reducing the knowledge gap". ${ }^{156}$

There is a further point too that needs to be underscored and addressed and that is, as one Cabinet Office representative put it, the 'huge issue of public trust' surrounding information sharing. The suggestion is that government has to overcome the panic that is set amongst those members of the public whenever a data sharing issue or proposal comes into the news. To deal with this, government needs to get its messaging right. As the official commented: "If you said to someone would you like your passport application to take two days instead of two weeks and that could be done with information sharing (hypothetical example) then they would likely jump at this. We tried to address this in 'smarter government' but are not sure how much we succeeded". Moreover, "a key barrier that the e-government unit and successor units have been faced with is sharing information across frontline services. We just cannot seem to crack that."

In marking the outgoing government's card over its recent approach towards NIP and endeavouring to answer the question posed at the outset of this paper viz., whether government responses to recent policy reviews can be said to amount to a coherent reform plan for NIP, it is clear that some breakthroughs in thinking have emerged. Whether this is due to forward thinking, prime ministerial determination, or simply that new ideas emerged through force of circumstance, is open to judgement. What is absolutely clear, however, is that there is still much more to be done. It is the right ambition but further investment will be needed and finding the resources to fund this will be hard. Inevitably, information policy is likely to be permanently in need of scrutiny, but government appears to be beginning to understand that developing a sound NIP is not just an end in itself, but a critical part of what must be done to deliver on the broader fronts of supporting the knowledge economy and facilitating social development. It is also an important instrument of reform available to the coalition government as the latter attempts to deliver its austerity programme and to retain its core deliverables. One is left with the hope that sufficient strength lies within the impetus created for these initiatives to endure and for matters to be taken forward. ICT offers some golden opportunities to do this and openness in making public data public must be right. What is needed now is a government ready to listen and find the resources to promote a smarter government. The 'smarter government' proposal is the most radical attempt yet to move the policy forward, particularly as it sets out specific actions with deadlines. In many respects, as discussed earlier in this paper, it is an agenda that transcends political parties as it is essentially driven by external market forces. The question now is whether the coalition government is ready and able to build on these foundations.

\section{Acknowledgements}

I would like to thank those members of the Civil Service with whom I have had conversations for their advice and comment. 


\section{Notes}

1 The Power of Information - An independent review by Ed Mayo and Tom Steinberg (June 2007).

2 The INSPIRE Regulations 2009 S.I. 2009 No. 3157.

3 Directive 2007/2/EC of 14 March 2007 establishing an Infrastructure for Spatial Information in the European Community (INSPIRE).

4 Place matters: the location strategy for the United Kingdom (Communities and Local Government/Geographic Information Panel, November 2008).

5 An Overview of the Benefits of Ensuring Digital Continuity (Final Draft, 19 November 2009). See also: Archives for the 21st Century CM 7744 (Presented to Parliament by the Lord Chancellor and Secretary of State for Justice, November 2009).

6 A Trading Fund is an operation of a government department that has been established by a Trading Fund Order in accordance with the Government Trading Funds Act 1973 (as amended by the Government Trading Act 1990).

7 Policy options for geographic information from Ordnance Survey - Consultation (Communities and Local Government, December 2009).

8 See for example: Richard Thomas and Mark Walport, Data Sharing Review Report (11 July 2008) building on the Information Commissioner's Office 'Framework code of practice for sharing personal information (October 2007).

9 See: The United Kingdom Report on the Re-use of Public Sector Information 2009 unlocking psi potential Cm 7672 (Presented to Parliament by the Lord Chancellor and Secretary of State for Justice, July 2009).

10 See new licensing model for re-use of government information described by the Office of Public Sector Information at www.opsi.gov.uk.

11 Digital Economy Act 2010 Ch. 24.

12 Marine and Coastal Access Act 2009 Ch. 23.

13 Protecting Information in Government (Cabinet Office, January 2010) which builds on the Data Handling Procedures in Government: Final Report (Cabinet Office, June 2008) and Protecting Government Information - Independent Review of Government Information Assurance - The Coleman Report (Commissioned by the Cabinet Office, June 2008).

14 'Making Public Data Public' project announced by the Prime Minister in June 2009 and described as an initiative to 'unlock innovation' by improving access to the 'wealth of government data', see http://data.gov.uk. This was followed in March 2010 by $£ 30$ million of government investment in a new Institute for Web Science, to be led by Tim Berners Lee and Nigel Shadbolt to work with government and business "to realise the social and economic benefits of advances in the web".

15 Information matters: building government's capability in managing knowledge and information (Knowledge Council, HM Government, November 2008).

16 Putting the Frontline First: smarter government $\mathrm{Cm} 7753$ (Presented to Parliament by the Chief Secretary to the Treasury, December 2009).

17 See: Cross cutting review of the knowledge economy (HM Government, 2000).

18 Transformational Government - Enabled by Technology (HM Government, 2005).

19 Op. cit., note 1 ante para. 39.

20 Smarter, Faster, Better e-Government - 8th Benchmark Measurement (Capgemini, Rand Europe, IDC, Sogeti \& DT1, November 2009).

21 This is outlined in a paper entitled 'An enterprise approach to Web 2.0 in government' on the Microsoft Government page at: http://www.microsoft.com/industry/government/guides/gov20.aspx. 
22 For example, understanding what drives high performance and better measures for judging this, as well as new models for the delivery of priorities including the participation of non-governmental parties. Ibid. pp.9-10.

23 For example, 'cloud computing' - virtualisation and sharing of computing assets across organisations. Ibid, p.9.

24 Op. cit. note 1, ante. The terms of reference of the Review were "to explore new developments in the use of communication of citizen- and State- generated public information in the UK, and to present an analysis and recommendations to the Cabinet Office Minister as part of the Policy Review. The Review is focused upon public information and excludes discussion about individuals' private data that may be held by the public sector."

25 Tom Steinberg has since founded and directed 'mySociety' - a non-profit, open source organisation that runs a series of democracy web sites in the UK such as 'TheyWorkForYou' and 'FixMyStreet'. 'mySociety' is a project of 'UKCitizens Online Democracy' (UKCOD) a registered charity in England and Wales.

26 Op. cit. note 1 ante, p.3.

27 The Government's Response to The Power of Information: An independent review by Ed Mayo and Tom Steinberg (2007) (June 2007).

28 The Task Force comprises individuals drawn from government, industry and the third sector "who all share a passion for using ICT to enable better public service delivery".

29 Power of Information Taskforce Report (February 2009).

30 A wiki is a website that facilitates the "easy creation and editing of any number of interlinked web pages via a web browser using simplified markup language or WYSIWYG text editor. Wikis are typically powered by wiki software and are often used to create collaborative websites, to power community websites, for personal note taking, in corporate intranets, and in knowledge management systems". (source: Wikipedia).

31 Ibid., Recs 1-2.

32 Ibid., Recs 3-4.

33 Ibid., Recs 5-6.

34 Ibid., Rec. 7.

35 Ibid., Recs 8-17.

36 Ibid., Rec 18-25.

37 See http://www.cabinetoffice.gov.uk/civil_service_reform.aspx.

38 Organisations in the third sector normally share the common characteristics of being non-governmental; value driven; and principally committed to the reinvestment of any financial surpluses to further social, environmental or cultural objectives. The term encompasses voluntary and community organisations, charities, social enterprises, cooperatives and mutuals both large and small. (See: http://www.cabinetoffice.gov.uk/the_third_sector.aspx.

39 See: www.appsi.gov.uk.

40 Information matters: building government's capability in managing knowledge and information (HM Government, November 2008).

41 Ibid., Foreword by Sir Gus O'Donnell, Cabinet Secretary and Head of the Home Civil Service.

42 Data Handling Procedures in Government: Final Report, (Cabinet Office, June 2008)

43 Ibid., para 3.

44 Ibid., p. 2 'Why information matters'.

45 Ibid., p. 4, 'The strategy'.

46 Ibid., p.10, Building a knowledge management and knowledge sharing culture.

47 Cabinet Office names Director of Digital Engagement (CAB035/09) 13 May 2009. 
48 Presentation: 'Extending Digital Engagement across government' Making government work better (Cabinet Office, 2009).

49 See for example http://digitalengagement.org/ which has published a 'Digital Engagement Manifesto' and aims to create "a collaborative, inclusive online space for those involved in the use of social technology for social benefit. We want to bring policymakers and practitioners together in areas covering digital inclusion, social innovation and e-democracy to shape a new, wider debate and set of ideas and practices".

50 'The widget economy enters the mainstream' (Times Online 20 June 2007).

51 Op.cit, note 14 , ante.

52 Op. cit., note 47 , ante.

53 Op. cit., note 48 , ante.

54 Op. cit., note 16, ante. Other tasks went to Martha Lane Fox - to accelerate the move to digitalised public services; Sir Michael Bichard - on letting local areas set priorities and guide resources; Martin Read - on improving the back office functions of government to the very highest standard; and Martin Jay on securing better procurement deals through better collaboration across the public sector.

55 Ibid., p.57.

56 Ibid., p.26. This followed a Cabinet Office pilot designed to test the proposition.

57 Ibid., p.26.

58 Ibid., p.27. See also note 16 , ante.

59 Ibid., p.13.

60 This is discussed in his book The Idea of Justice (Allen Lane, p.496).

61 In addition to its conferences is 'TEDTalks' in which leading thinkers have the opportunity to share key ideas in talks lasting less than 20 minutes. These are released online to a global audience of millions. The TED Open Translation Project brings TEDTalks to the non-English-speaking world by offering subtitles, interactive transcripts and the ability for any talk to be translated by volunteers worldwide.

62 TED also offers three TED prizes of $\$ 100,000$ every year to exceptional individuals with 'one wish to change the world'. TED maintains that these 'wishes' have led to collaborative initiatives with far reaching consequences.

63 Attended by more than 1,000 people content has expanded "to include science, business, the arts and global issues facing our world". Over four days 50 speakers each take an 18 minute slot to present ideas. There are no breakout sessions.

64 To date more than 500 TEDTalks have been published. The videos are released under a Creative Commons licence, so they can be "freely shared and reposted". Contributors to TED include Tim Berners Lee who discusses opening up public data on "The Year open data went worldwide" (Filmed Feb 2010, Posted Mar 2010).

65 There are private sector 'information visualisation' projects too such as 'Many Eyes' the IBM Research project and website whose stated goal is "to enable data analysis by making it easy for laypeople to create, edit, share and discuss information visualizations". It was started in 2007 by Fernanda Viejgas and Martin M. Wattenberg. See: $\mathrm{http}: / /$ manyeyes.alphaworks.ibm.com/manyeyes/page/About.html.

66 The comment about the talk on TED reads: "What sets Rosling apart isn't just his apt observations of broad social and economic trends, but the stunning way he presents them. Guaranteed: You've never seen data presented like this. By any logic, a presentation that tracks global health and poverty trends should be, in a word:boring. But in Rosling's hands, data sings. Trends come to life. And the big picture - usually hazy at best - snaps into sharp focus".

67 David Cameron, 'The next age of government' TEDTalk (Feb 2010) at http://www.ted.com. Gordon Brown also spoke on TED in July 2009 with a TEDTalk entitled: 'Winning a web for global good' in which he argues that "today's interconnected [can be used] to develop our 
shared global ethic - and work together to confront the challenges of poverty, security, climate change and the economy".

68 The vision is to move away from "top down monolithic websites broadcasting public service information in the hope that the people who need help will find it - to government on demand... where citizens will be in control - choosing content relevant to them and determining their level of engagement”. See: http://www.number10.gov.uk/Page22897.

69 Ibid

70 This programme was launched by HM Treasury in July 2008 to deliver efficiency savings in a number of cross cutting areas. Themes emerging aimed to achieve consistent comparable data, incentives to deliver high quality public services using the right structures and tools, alongside accountability and performance management.

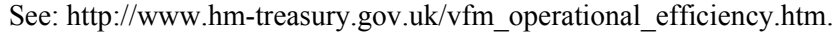

71 The Shareholder Executive was created in September 2003 "to improve fundamentally the government's performance as a shareholder in government-owned businesses and to provide a source of corporate finance expertise within government... Our role is to be a proactive intelligent shareholder, working with government departments and management teams to help government-owned businesses to perform better". See: http://www.shareholderexecutive.gov.uk.

72 This is the 'beta' version of the data.gov.uk website launched by the Minister for Digital Britain in January 2010 commencing with the release of 2,500 data sets via the website.

73 The objective of the Location Strategy for the UK is to "maximize the value to the public, government, UK business and industry of geographic information." Its aim is to provide a "consistent framework to assist national, regional and local initiatives and service delivery". See: http://www.communities.gov.uk/publications/communities/locationstrategy.

74 The Location Council, chaired by Defra's Director of Strategy and Evidence Group, provides leadership and strategic direction for the implementation of the UK Location Strategy and the INSPIRE Directive. See post.

75 This comprises the register of unpublished information holdings developed by OPSI to make IAR records of Crown bodies available on OPSI's Inforoute website. This serves as a single point of access to the public to identify unpublished government information, which holds it and whom to contact. See: http://www.bis.gov.uk/site/foi/information-asset-register.

76 This was proposed by the Science and Innovation Ministerial Committee of the Cabinet to consider how government could realise the potential benefits of real-time and archived data and the formation of a "cross-government data-mashing lab" to realise innovative mash-ups. This was in many respects the precursor to the current data.gov initiative.

77 The Information Fair Trader Scheme "sets and assesses standards for public sector bodies", encouraging re-use of PSI according to "standards of fairness and transparency".See: http://www.opsi.gov.uk/ifts/index.

78 Re-use of Public Sector Information Regulations S.I. 2005 No. 1515.

79 'Exploiting government's information assets for the public good' - note setting out APPSI's view "on how best to proceed".

80 These are Companies House, The Met Office, Ordnance Survey, The UK Hydrographic Office, The Land Registry and The Driver and Vehicle Licensing Agency (DVLA). See further: Saxby S. (2008) 'Public sector information and re-use policy - where is the UK now?', Int. J. Private Law, Vol. 1, Nos 3/4, pp.229-256.

81 Newbery, Bently \& Pollock 'Models of Public Sector Information Provision via Trading Funds' (26 February 2008).

82 Ibid., p.2.

83 Ibid., pp.123-124.

84 The Guardian Newspaper's 'Free our Data' campaign in particular.

85 Ruth Keeling, 'Mapping the future' (Civil Service Live, 4 December 2009). See: http://network.civilservicelive.com/pg/pages/view/264054. 
86 Op. cit., note 17 , ante.

87 The Commercial Use of public information OFT 861 (Office of Fair Trading, December 2006).

88 Op. cit., note 80 , ante.

89 Operational Efficiency Programme: final report (HM Treasury, April 2009). The OEP set out recommendations for "increasing efficiencies across a range of areas in the public sector, including assets and property, collaborative procurement, and back office and IT".

90 A summary of the process is set out in Re-use of Public Sector Information 2009 report, Ch. 4, op. cit., note 9 , ante.

91 Op. cit., note 7, ante.

92 Office of Public Sector Information to guide Ordnance Survey's new business strategy (OPSI, 23 April 2009).

93 Op. cit., note 84 , ante.

94 Michael Cross, The Guardian, 'Ordnance Survey hires PR company to lobby politicians' (21 August, 2008).

95 Op. cit., note 85 , ante.

96 Op. cit., note 14, ante.

97 Op. cit. note 85, ante. Ruth Keeling attributes this theory to Ed Parsons, former Chief Technology Officer at Ordnance Survey until he left to join Google in 2006.

98 Re-mapping the future for Ordnance Survey - making public data public, (Communities and Local Government, 17 November 2009).

99 Op. cit., note 85, ante. Ruth Keeling reports this to be the view of Ben Middleton, negotiator for the public sector trades union, Prospect, that represents may workers at Ordnance Survey. He suggests that the addition of the word "delighted" attributed to the OS Chairman in the press release was a "late addition that appeared on web versions of the government press release." Keeling reports him saying that it was "not clear to what extent OS were aware of what was being announced" at that time.

100 Op. cit., note 7 , ante.

101 Ibid., p.10. Option 1 of the Consultation would allow Ordnance Survey to "cover its costs and fund its investment programme without requiring additional contributions from government".

102 In essence the strategy was "to promote innovation ....reform Ordnance Survey's licensing framework ...reducing costs over time ...supporting the sharing of information across the public sector - to enable better public policy and services [and] ...creating an innovative trading entity [in Ordnance Survey]. Op. cit., note 9, ante, p. 26.

103 Op. cit., note 91, ante, p.10. This followed a Trading Funds Assessment, announced at Budget 2008 to be conducted by the Shareholder Executive. See note 89, ante. The OEP on specific assets continues, including several trading funds, with the intent to produce reports on a six monthly basis.

104 This is another name for the 'Berners Lee/Shadbolt data.gov initiative' op. cit., note 14, ante.

105 Ibid., p. 10.

106 Op. cit., note 100, ante pp.9-11.

107 Policy Options for geographic information from Ordnance Survey - Consultation Government Response (Department for Communities and Local Government, March 2010).

108 Op. Cit., note 98 , ante.

109 Op. cit., note 107, ante. To be known as OS OpenData ${ }^{\mathrm{TM}}$ the datasets to be released are those set out in the original consultation document as a Free package with some changes: replacement of the 1:25000 and 1:50000 Scale Colour Raster products with OS VectorMap District; addition of OS Locator ${ }^{\mathrm{TM}}$ and Land-Form PANORAMA to the product list; and replacement of Code-Point by Code-Point Open, which provides "accurate locations for 1.7 million postcodes in England, Scotland and Wales". 
110 Provision of such an agreement will "allow government to make geographic information provided by Ordnance Survey, including high specification OS MasterMap products, free at the point of use for public sector bodies, and subject to no limits on re-use when used internally within the public sector for public sector activities". This change is intended to come into effect on 1 April 2011.

111 Derived data: "where data is created against an Ordnance Survey map back-drop, OS claim intellectual property rights on the data created. This then limits the ability to share the data without being adversely affected by confusing and restrictive licensing regulations". Comment from Leeds City Council in its response to the Consultation date 18 March 2010.

112 The stated aim is that derived data issues should "not unnecessarily impede the release of public datasets by other public bodies, balancing the significance of the data taken, the impact of release of any dataset on Ordnance Survey's commercial business and that of its partners, and any legal or regulatory consequences for Ordnance Survey". Op. cit., note 107, ante, p.9. The comment from Leeds City Council is that: "if the derived data issue is not resolved then little progress will have been made in truly moving forward with the innovative use of spatial data, regardless of whether a few raster datasets are made free or not". Op. cit., note 111, ante.

113 The government has identified OS, as a data management and delivery-focused organisation, as being best placed to "deliver Britain's obligations" under INSPIRE (see note 3, ante). It will use Open Source software and G-cloud (cloud computing) processes where appropriate and will "design, specify, create and acceptance test repeatable INSPIRE compliant hosted services, together with an overarching portal to support the View and Metadata Services. These platforms will be offered back to the community as Open Source software". Op. cit., note 107, ante, p. 21.

114 Op. cit., note 39 , ante.

115 APPSI's response to CLG consultation on Policy Options for geographic information from OS (March 2010).

116 Ibid., Executive Summary para. (i).

117 Ibid., p. 1(ii). See also note 106, ante.

118 Op. cit., note 115 , ante, para 2.1 .

119 For example at para 2.11 , the ability today, while on foot or in a car, to collect " $5 \mathrm{~m}$ resolution GPS data on the location of roads, houses, fences etc. APPSI also points to "the advent of "crowd sourcing' operations like 'OpenStreetMap" which "shows what can be done using freely available GPS facilities".

120 Op. cit., note 16 , ante.

121 Ibid., p. 26.

122 Ibid., p. 4 and footnote 4.

123 Ibid., para 2.5 .

124 Local Government Association/Improvement and Development Agency Response to the Communities and Local Government Inquiry into Ordnance Survey (March 2010). Memorandum para 3.

125 Ibid. para 2.2. The Location Council defines the following CRG's: Geodetic Framework; Topographic Mapping (at different resolutions and including ground height information); Geographic Names; Addresses; Streets; Land and Property Ownership; Hydrology/Hydrography; Statistical Boundaries; and Administrative boundaries.

126 'Does the House next door really exist?' (The Royal Statistical Society press release 9 July 2009).

127 Migration Statistics: the Way Ahead (UK Statistics Authority, July 2009) para 63.The report points out that The National Gazetteer has been developed for Scotland "to provide an accurate, up to date database of land and property data/assets for use by Scottish councils and other parts of the public sector". It remarks that "the Scottish experience could inform the development of an address register for the rest of the UK". Ibid. footnote 39. 
128 IDeA aims to improve public services by supporting self-sustaining improvement from local government.

129 Letter by the Chairman of IDeA to Minister of State for Housing and Planning (28 July 2009).

130 For example Ernestmarples.com (named after the Postmaster General who introduced UK postcodes) has had to curtail its activities due to threats of legal action. This in turn has affected other sites such as Job Centre Pro Plus; Healthware (locates nearby pharmacies and hospitals); Planning alerts.com (Monitors planning applications) and others.

131 Source: from BBC News: 'Legal threat closes postcode feed'.

132 Op. cit., note 107 , ante, para 4.70.

133 Ibid., para 4.72. The problem of intellectual property rights arose in evidence given by a Treasury minister to the House of Commons Treasury Committee enquiry 'Counting the population' in 2008 and again in the 2009 Power of Information Taskforce report which urged creation of "a freely available single definitive address and postcode database for the UK". (Source: op. cit., Comment made in a letter by the Chair of UK Statistics Authority to the Minister of State for Housing (8 July 2009).

134 Op. cit., note 115 ante, para 3.51.

135 Treasury - Eleventh Report (Treasury Select Committee, 14 May 2008) para 91.

136 Office for National Statistics - 'The case for the 2011 Census'.

137 Op. cit., note 135 ante, para 92.

138 London's population and the 2011 Census HC 349 First Report of Session 2009-10 (House of Commons London Regional Committee, 31 March 2010).

139 The LRC is appointed by the House of Commons to examine regional strategies and the work of regional bodies.

140 Ibid., para 88.

141 See further note 4 ante. Also: UK Location Programme 'Conceptual Design' (Manning/Murray, December 2009); A guide to the UK Location Information Infrastructure (December 2009) and 'UK Location Information Infrastructure Roadmap' (Tim Manning, February 2010) - "The purpose of the UKLII Roadmap is to set out the implementation approach to be adopted in the delivery of UK location information infrastructure. This will be used to drive the development of the overall UK Location Programme Plan and lower level project plans". Ibid. p.14.

142 See further the Marine and Coastal Access Act 2009 which "creates a new marine planning system designed to bring together the conservation, social and economic needs of our seas". The Bill was introduced by DEFRA and obtained Royal Assent on 12 November 2009. The Royal Town Planning Institute comment that "Marine spatial planning is the idea that, just as on land, the sustainable development of our marine environment requires to be holistically managed with reference to information about the effects of use and development. Decisions should be made to achieve sustainable development, having regard to planning policies prepared using the best available data". Source: http://www.rtpi.org.uk/item/770/23/5/3.

143 Op. cit., notes 2, 3 and 113, ante.

144 See further: Saxby S. (2010) 'National archives and records - the legal and policy considerations for the UK', Int. J. Private Law, Vol. 3, Nos 1/2, pp.43-70.

145 A very good example is MEDIN - Marine Environmental Data \& Information Network - a network of sponsoring organisations that have come together to promote the sharing of, and improved access to, a range of marine data through a prototype central discovery metadata portal and by the setting of standards for use by MEDIN partners. MEDIN does not itself hold intellectual property rights hence the importance of finding solutions to licensing issues including that of derivative rights. MEDIN has "over 30 partners representing the whole marine sector: government departments, research institutions and private value-adding companies". See further: http://www.oceannet.org/about_us/.

146 Brian Wheeler, 'Web revolution sweeps Whitehall' at http://news.bbc.co.uk/1/hi/uk_politics/8680949.stm. 
147 Ibid.

148 Comment by David Thomas, Director of Technology at The National Archives. He also believes that the UK has "the only government archive in the world regularly capturing and preserving government websites" and that "the ephemeral nature of websites means there's a risk that important information could be lost without a comprehensive web archiving programme".

149 Government and the Internet Report (Central Office of Information, 24 June 2010). Public Accounts Committee has requested a standard way of measuring and reporting costs for websites be introduced, which COI has delivered in its report.

150 See note 24 , ante.

151 See note 16 , ante.

152 See notes 14 and 98 , ante.

153 See notes $114-118$, ante.

154 See note 11 , ante.

155 Copyright in the Knowledge Economy [COM(2009) 532 final, Brussels, 19.10.2009].

156 WIPO Director General highlights importance of intellectual property for innovation and technology transfer (PR/2010/640 10 May 2010). Libraries, for example, argue that the "current system of copyright provisions governing library activity is insufficient for a durable and sustainable global information society", e.g., "flexibilities have not expanded with enhanced rights and obligations... and do not sufficiently address digital activity, or cross-border distribution of works. Private licensing often prevents certain uses of works, and technological protection measures prevent uses that copyright law has long intended to support". Source: Statement from Library Copyright Alliance and Electronic Information for Libraries to WIPO Committee on Development and Intellectual Property, Fifth Session, Geneva, 26-30 April, 2010. 